\title{
Conformational Space and Vibrational Spectra of Methyl 4-Chloro-5-phenyl-1,3-oxazole-2-carboxylate
}

\author{
Susy Lopes, ${ }^{\dagger}$ Cláudio M. Nunes,${ }^{\dagger}$ Andrea Gómez-Zavaglia, ${ }^{\dagger, \dagger}$ Teresa M. V. D. Pinho e Melo, ${ }^{\dagger}$ \\ and Rui Fausto*, ${ }^{*}$ \\ Department of Chemistry, University of Coimbra, P-3004-535 Coimbra, Portugal, and Centro de Investigación y \\ Desarrollo en Criotecnología de Alimentos (Conicet La Plata, UNLP), RA-1900 La Plata, Argentina
}

Received: April 23, 2010; Revised Manuscript Received: June 29, 2010

\begin{abstract}
Methyl 4-chloro-5-phenyl-1,3-oxazole-2-carboxylate (MCPOC) has been synthesized and isolated in cryogenic matrices (argon and xenon). FTIR spectroscopy studies on the matrix isolated compound, supported by DFT(B3LYP)/ 6-311++G(d,p) calculations, allow for the identification of two low-energy conformers (I and II) of the molecule, which differ from each other in the orientation of the ester group relative to the oxazole ring. In both these conformers, the ester moiety is in the s-cis configuration $\left(\mathrm{O}=\mathrm{C}-\mathrm{O}-\mathrm{CH}_{3}\right.$ dihedral: $\left.0^{\circ}\right)$. Conformer $\mathbf{I I}$ is ca. $3.0 \mathrm{~kJ} \mathrm{~mol}^{-1}$ higher in energy than form $\mathbf{I}$ in the gas phase. Two additional higher energy conformers, III and IV, with relative energies of ca. 30 and $45 \mathrm{~kJ} \mathrm{~mol}^{-1}$, respectively, were predicted to exist by the calculations, corresponding to structures where the ester group is in an approximately s-trans arrangement. Annealing of the compound isolated in xenon at $60 \mathrm{~K}$ led to aggregation and simultaneous reduction of the population of $\mathbf{I}$ compared to that of the more polar conformer II. These results suggest the inversion of the order of stability of the two conformers in that matrix, eventually accompanied by a higher trend of conformer I to aggregate. Full assignment of the observed infrared bands to the two experimentally accessible conformers was carried out for the matrix isolated monomeric species. In addition, the infrared spectra of the neat compound in the low-temperature $(10 \mathrm{~K})$ amorphous and crystalline phases, as well as the infrared and Raman spectra of the crystal at room temperature were also obtained and assigned.
\end{abstract}

\section{Introduction}

Oxazole is a five-membered heterocyclic compound that contains the $\mathrm{N}=\mathrm{C}-\mathrm{O}$ moiety. The oxazole ring occurs naturally in numerous living systems, such as marine organisms, plants (e.g., coffee, peanuts), and mushrooms. ${ }^{1-9}$ In recent years, an increasing number of studies have been developed dealing with the total synthesis of natural products bearing oxazole moieties with interesting biological activities. In particular, oxazole containing molecules isolated from marine organisms constitute an ever-growing number of natural products that have been receiving different pharmacological uses (as anti-inflammatory, antibacterial, antibiotic, antiviral, analgesic, and antitumor drugs). ${ }^{3,4,10-26}$ Some oxazoles display scintillator properties ${ }^{27,28}$ and are used as fluorescent whitening agents ${ }^{29,30}$ and in dyes and pigments. ${ }^{31}$ The practical uses of oxazoles extend to other industrial applications such as pesticides, the production of electrophotographic materials, additives to detergents, and hydraulic fluids and lubricants. ${ }^{32}$

Because of their known multiple practical uses, aryl- and alkyloxazoles have been extensively studied both experimentally and theoretically. ${ }^{33-43}$ On the other hand, halogen-substituted oxazoles are a relatively new family of compounds which, in spite of its relevance as synthetic intermediates in carbon-carbon bond making reactions ${ }^{44,45}$ have been paid little attention. In a previous publication ${ }^{46}$ we described the first structural assignment of methyl 4-chloro-5-phenyl-1,3-oxazole-2-carboxylate (MCPOC) in an argon matrix. In such a study, we were able to confirm that the thermolysis product of methyl 2-benzoyl-2-choro- $2 \mathrm{H}$-azirine-3-

\footnotetext{
* Corresponding author. E-mail: rfausto@ci.uc.pt.

${ }^{\dagger}$ University of Coimbra.

* Centro de Investigación y Desarrollo en Criotecnología de Alimentos.
}

carboxylate was MCPOC and not the isoxazole 4-choro-5phenylisoxazole-3-carboxylate as previously suggested. ${ }^{47}$

In the present study, the conformational space of MCPOC was investigated in detail by concerted matrix-isolation infrared spectroscopy (in both argon and xenon matrices) and quantum chemical theoretical [DFT(B3LYP)/6-311++G(d,p)] approach. As will be described in detail in the next sections, from these studies it was possible to conclude on the existence of two significantly populated conformers of MCPOC in the gas phase and in the cryogenic matrices (argon, xenon), and of two higher energy forms. The two experimentally relevant low-energy conformers were successfully characterized and the obtained experimental spectra interpreted. The infrared spectra of the neat compound in the low-temperature $(10 \mathrm{~K})$ amorphous and crystalline phases, as well as the infrared and Raman spectra of the crystal at room temperature were also obtained and assigned.

\section{Experimental and Computational Methods}

The procedure for the synthesis of methyl 4-chloro-5-phenyl1,3-oxazole-2-carboxylate (MCPOC) has been reported elsewhere. ${ }^{46}$

Matrices were prepared by codeposition of MCPOC vapors coming out from a specially designed thermoelectrically heatable mini-furnace, assembled inside the cryostat (APD Cryogenics, model DE-202A) chamber, and large excess of the matrix gas (argon, N60; xenon, N48, both obtained from Air Liquide) onto the CsI substrate cooled to $10 \mathrm{~K}$ (for argon matrices) and $20 \mathrm{~K}$ (for xenon matrices). The IR spectra were recorded with 0.5 $\mathrm{cm}^{-1}$ spectral resolution in a Mattson (Infinity 60AR Series) Fourier Transform infrared spectrometer, equipped with a deuterated triglycine sulfate (DTGS) detector and a $\mathrm{Ge} / \mathrm{KBr}$ 
beam splitter. Necessary modifications of the sample compartment of the spectrometer were done to accommodate the cryostat head and allow purging of the instrument by a stream of dry nitrogen, to remove water vapors and $\mathrm{CO}_{2}$.

The low-temperature solid amorphous layer was prepared in the same way as matrices but with the flux of a matrix gas cut off. The layer was then allowed to anneal at a slowly increasing temperature up to $280 \mathrm{~K}$, and crystallization of the amorphous layer occurred. After recording of the infrared spectrum of the obtained crystal, the sample was cooled back again to $10 \mathrm{~K}$ and a new spectrum of the crystalline phase was collected.

$\mathrm{KBr}$ pellets and Nujol mulls containing MCPOC were prepared by standard procedures. Their IR spectra were collected at room temperature using a BOMEM (MB40) spectrometer, with a Zn/ Se beam splitter and a DTGS detector, with $4 \mathrm{~cm}^{-1}$ spectral resolution. The Raman spectrum of solid MCPOC in the 3380-100 $\mathrm{cm}^{-1}$ range was acquired at room temperature using a dispersive Raman instrument, model DXR SmartRaman, from Thermo Fisher Scientific, equipped with a low-power, externally stabilized diode laser $(\lambda=780 \mathrm{~nm})$, with a maximum power at output of laser head of $14 \mathrm{~mW}$ and a $3.0 \mathrm{~mm}$ beam diameter. The data were collected with an exposure time to laser radiation of $99 \mathrm{~s}, 100$ sample exposures and a slit aperture of $25 \mu \mathrm{m}$.

The quantum chemical calculations were performed with Gaussian $03^{48}$ at the DFT level of theory, using the split valence triple- $\zeta$ 6-311++G(d,p) basis set ${ }^{49}$ and the three-parameter B3LYP density functional, which includes Becke's gradient exchange correction ${ }^{50}$ and the Lee, Yang, and Parr correlation functional. ${ }^{51}$

Geometrical parameters of the different conformations were optimized using the geometry direct inversion of the invariant subspace (GDIIS) method ${ }^{52,53}$ and the synchronous transit-guided quasi-Newton (STQN) method ${ }^{54}$ was used to locate the transition states for conformational isomerization. To assist the analysis of the experimental vibrational spectra, wavenumbers, IR intensities, and Raman scattering activities $\left(S^{\mathrm{R}}\right)$ were also calculated at the same level of approximation. Theoretical Raman intensities $\left(I^{\mathrm{R}}\right)$ were obtained from the calculated Raman scattering activities according to the expression $I^{\mathrm{R}}(i)=10^{-12}\left(v_{0}\right.$ $\left.-v_{\mathrm{i}}\right)^{4} v_{\mathrm{i}}^{-1} S^{\mathrm{R}}(i)$, where $v_{0}$ is the excitation wavenumber and $v_{\mathrm{i}}$ is the calculated wavenumber of the normal mode $i .^{55}$ The computed harmonic frequencies were scaled down by a single factor, 0.9835, obtained from linear fitting of the calculated to experimental wavenumbers (measured in xenon matrix), to correct them for the effects of basis set limitations, neglecting part of electron correlation and anharmonicity effects. The nature of stationary points on the potential energy surface was checked through the analysis of the corresponding Hessian matrix.

Normal coordinate analysis was undertaken in the internal coordinates space, as described by Schachtschneider ${ }^{56}$ and the optimized geometries and harmonic force constants resulting from the DFT(B3LYP)/6-311++G(d,p) calculations. The internal coordinates used in this analysis were defined following the recommendations of Pulay et al. ${ }^{57}$

\section{Results and Discussion}

Potential Energy Landscape. The MCPOC molecule bears 4 conformationally relevant internal rotation axes, corresponding to rotations about the $\mathrm{C}_{1}-\mathrm{C}_{5}, \mathrm{C}_{17}-\mathrm{C}_{18}, \mathrm{C}_{18}-\mathrm{O}_{20}$, and $\mathrm{O}_{20}-\mathrm{C}_{21}$ bonds. To characterize structurally in detail the molecule, a systematic investigation of its potential energy surface was undertaken at the DFT(B3LYP)/6-311++G(d,p) level of approximation, where these four internal degrees of freedom were taken into account. These calculations showed that in all

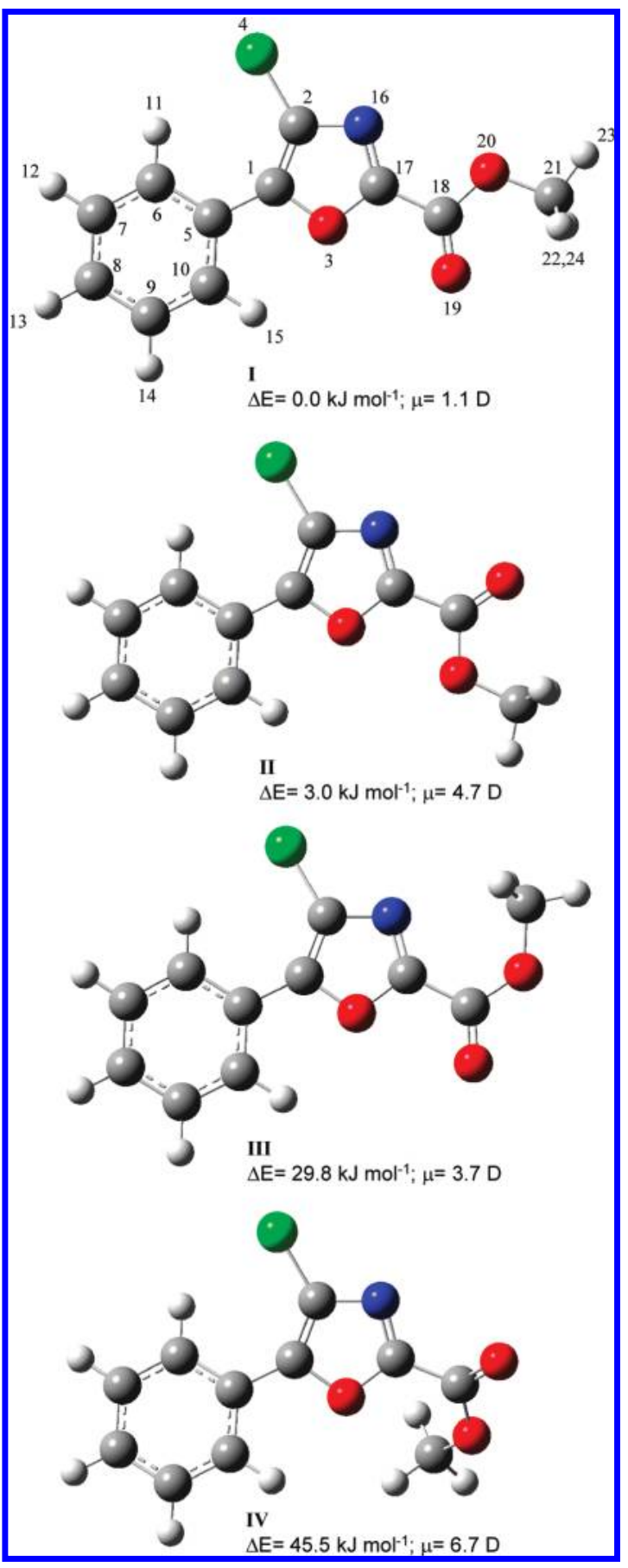

Figure 1. Minimum energy structures on the potential energy surface of MCPOC, with atom numbering. Relative energies, including zeropoint energy corrections $\left(\Delta E / \mathrm{kJ} \mathrm{mol}^{-1}\right)$ and dipole moments $(\mu / \mathrm{D} ; 1$ $\mathrm{D}=3.33564 \times 10^{-30} \mathrm{C} \mathrm{m}$ ) are also provided. III and IV correspond to pairs of symmetry-equivalent minima with $\mathrm{C}_{6}-\mathrm{C}_{5}-\mathrm{C}_{1}-\mathrm{O}_{3}$, $\mathrm{N}_{16}=\mathrm{C}_{17}-\mathrm{C}_{18}=\mathrm{O}_{19}$, and $\mathrm{O}_{19}=\mathrm{C}_{18}-\mathrm{O}_{20}-\mathrm{C}_{21}$ dihedral angles (deg) $+177.2,-172.5$, and -175.5 (or $-177.2,+172.5,+175.5)$ and +12.5 , +33.7 , and -161.0 (or $-12.5,-33.7$, and +161.0 ), respectively. However, because the transition state structure separating the two minima III lies below their zero point vibrational level, only conformer IV is doubly degenerated by symmetry, while III is a unique conformer with the most probable geometry at the geometry of the $C_{s}$ symmetry structure separating the two minima. Note that the dipole moment value for conformer II indicated in ref 46 was misprinted (1.71 D, instead of the right value, 4.71).

minimum energy conformations (Figure 1) the geometry around the $\mathrm{C}_{1}-\mathrm{C}_{5}$ and $\mathrm{O}_{20}-\mathrm{C}_{21}$ bonds; i.e., the configurations assumed by the phenyl group in relation to the oxazole ring and that of 


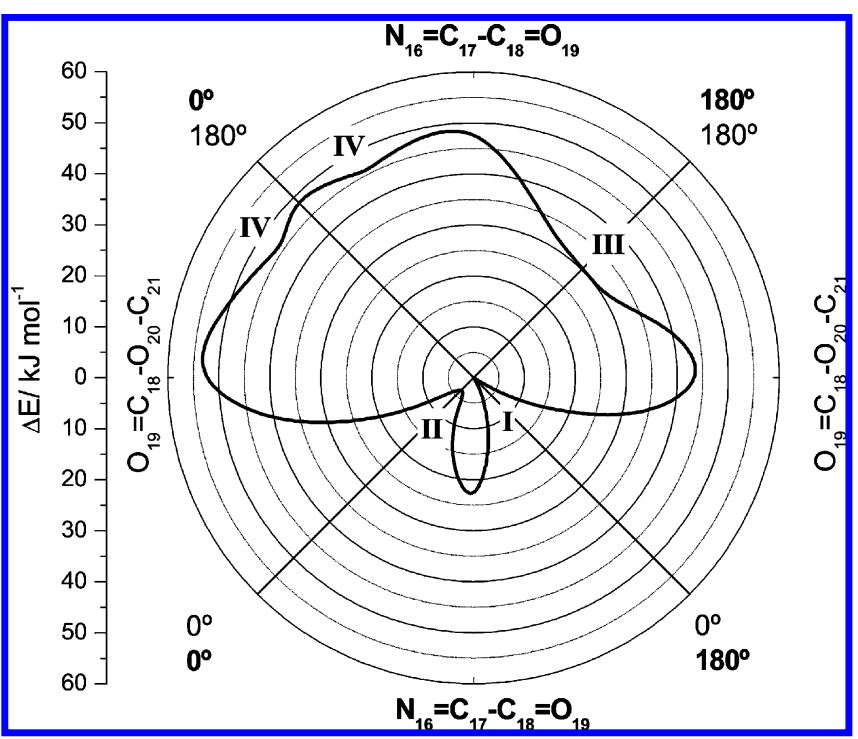

Figure 2. DFT(B3LYP)/6-311++G(d,p) calculated potential energy profiles for internal rotation around the $\mathrm{C}_{17}-\mathrm{C}_{18}$ and $\mathrm{C}_{18}-\mathrm{O}_{20}$ bonds. The curves were obtained by performing a relaxed scan on the potential energy surface of the molecule along the two relevant coordinates $\left(\mathrm{N}_{16}=\mathrm{C}_{17}-\mathrm{C}_{18}=\mathrm{O}_{19}\right.$ and $\mathrm{O}_{19}=\mathrm{C}_{18}-\mathrm{O}_{20}-\mathrm{C}_{21}$ dihedral angles $)$ in steps of $30^{\circ}$.

the methyl group, respectively, are the same: (i) the phenyl group and the oxazole ring are coplanar (or nearly coplanar), as could be expected considering the relevance of the $\pi$-electron delocalization between the two rings and the favorable interactions between $\mathrm{H}_{11}$ and the chlorine atom for this arrangement; (ii) the methyl group has one of its hydrogen atoms in the antiperiplanar position relative to the carbonyl group and the other two hydrogen atoms symmetrically placed out of the molecular plane and forming $\mathrm{H}-\mathrm{C}-\mathrm{O}-\mathrm{C}(=\mathrm{O})$ angles of ca. $\pm 60^{\circ}$, as happens usually in nonsterically hindered methyl esters. ${ }^{58-60}$

Rotations about the $\mathrm{C}_{17}-\mathrm{C}_{18}$ and $\mathrm{C}_{18}-\mathrm{O}_{20}$ bonds led to the existence of six minima on the potential energy surface of the molecule. Two of these minima are unique and belong to the $C_{s}$ point group. They correspond to the two most stable conformers of MCPOC, I and II (see Figure 1). In these conformers, the configuration about the ester $\mathrm{C}_{18}-\mathrm{O}_{20}$ bond is s-cis $\left(\mathrm{O}_{19}=\mathrm{C}_{18}-\mathrm{O}_{20}-\mathrm{C}_{21}\right.$ dihedral of $\left.0^{\circ}\right)$, whereas the $\mathrm{N}_{16}=\mathrm{C}_{17}-\mathrm{C}_{18}=\mathrm{O}_{19}$ dihedral is $180^{\circ}$ in the most stable conformer I, and $0^{\circ}$ in conformer $\mathbf{I I}$, which is ca. $3.0 \mathrm{~kJ} \mathrm{~mol}^{-1}$ higher in energy than form $\mathbf{I}$. The calculated barrier for the $\mathbf{I I} \rightarrow \mathbf{I}$ isomerization reaction is $20.5 \mathrm{~kJ} \mathrm{~mol}^{-1}$ (Figure 2). The other four minima correspond to two symmetry-equivalent pairs and are related with the higher energy conformers III and IV represented in Figure 1. Conformer IV is the highest energy form (relative energy of 45.5 $\mathrm{kJ} \mathrm{mol}^{-1}$ ). It exists as a doubly degenerated-by-symmetry form with $\mathrm{C}_{6}-\mathrm{C}_{5}-\mathrm{C}_{1}-\mathrm{O}_{3}, \mathrm{~N}_{16}=\mathrm{C}_{17}-\mathrm{C}_{18}=\mathrm{O}_{19}$, and $\mathrm{O}_{19}-\mathrm{C}_{18}-\mathrm{O}_{20}-\mathrm{C}_{21}$ dihedral angles of $+12.5^{\circ},+33.7^{\circ}$, and $-161.0^{\circ}$ (or $-12.5^{\circ}$, $-33.7^{\circ}$, and $+161.0^{\circ}$ ). The two equivalent-by-symmetry forms IV are separated by an energy barrier of $3.6 \mathrm{~kJ} \mathrm{~mol}^{-1}$, the transition state structure corresponding to the $C_{s}$ symmetry structure where the $\mathrm{C}_{6}-\mathrm{C}_{5}-\mathrm{C}_{1}-\mathrm{O}_{3}, \mathrm{~N}_{16}=\mathrm{C}_{17}-\mathrm{C}_{18}=\mathrm{O}_{19}$, and $\mathrm{O}_{19}=\mathrm{C}_{18}-\mathrm{O}_{20}-\mathrm{C}_{21}$ dihedral angles are $0^{\circ}, 0^{\circ}$, and $180^{\circ}$, respectively (see Figure 2). They are separated from conformer II by an energy barrier of 8.6 $\mathrm{kJ} \mathrm{mol}^{-1}$ (Figure 2). In the case of the two symmetry-equivalent minima related with conformer III the situation is different because they are separated by an energy barrier that is below the zero point vibrational level associated with the interconversion between them, making the transition state $C_{s}$ symmetry structure to be the most probable structure defining a unique conformational state.

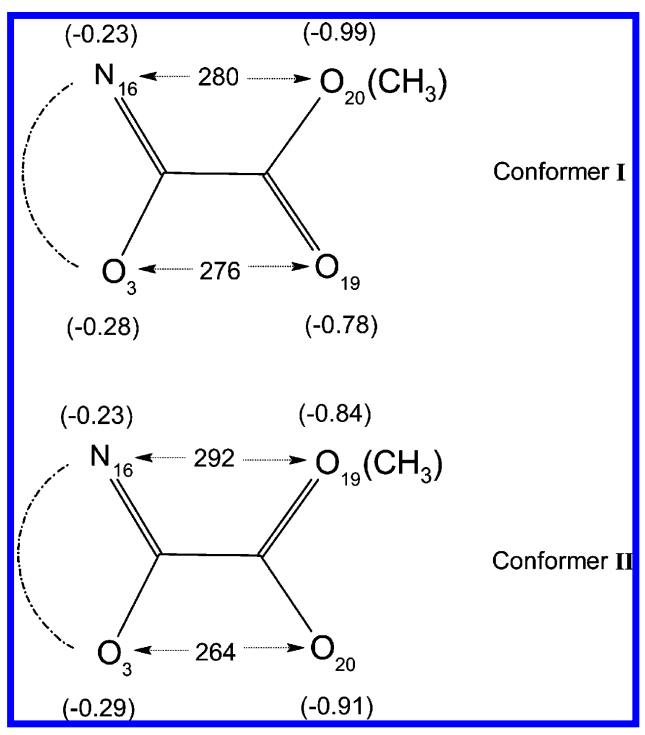

Figure 3. Calculated APT charges (units of electron; $1 \mathrm{e}=$ $1.602176487 \times 10^{-19} \mathrm{C}$ ) on selected atoms and distances $(\mathrm{pm})$ between these atoms in the two most stable MCPOC conformers.

The two minima have $\mathrm{C}_{6}-\mathrm{C}_{5}-\mathrm{C}_{1}-\mathrm{O}_{3}, \mathrm{~N}_{16}=\mathrm{C}_{17}-\mathrm{C}_{18}=\mathrm{O}_{19}$, and $\mathrm{O}_{19}=\mathrm{C}_{18}-\mathrm{O}_{20}-\mathrm{C}_{21}$ dihedral angles equal to $+177.2^{\circ},-172.5^{\circ}$, and $-175.5^{\circ}$, and $-177.2^{\circ},+172.5^{\circ}$, and $+175.5^{\circ}$, respectively, and in the most probable $C_{s}$ structure separating them these angles are $180^{\circ}, 180^{\circ}$, and $180^{\circ}$. Conformer III is $28.9 \mathrm{~kJ} \mathrm{~mol}^{-1}$ higher in energy than the most stable form and has energy barriers separating it from I and IV equal to 14.5 and $19.3 \mathrm{~kJ} \mathrm{~mol}^{-1}$, respectively (see Figure 2).

The reasons for the relative stability of the MCPOC conformers can be easily correlated with their structure. The large energy of conformer III relative to forms I and II results essentially from the fact that in the first form the arrangement of the ester group is the well-known less stable s-trans geometry, ${ }^{61-65}$ whereas in the latter this group is in the s-cis geometry. The difference in energy between III and I is indeed similar to those between the s-trans and s-cis conformers of methyl formate, acetate, and chloroacetate, for example, all of them of ca. 32 $\mathrm{kJ} \mathrm{mol}^{-1}{ }^{61-63}$ Conformer IV has also the ester group in the s-trans arrangement, but its energy is even larger than that of conformer III due to the unfavorable strong repulsive steric interaction between the methyl ester group and the oxazole ring. This interaction (directly and through the reduction in the $\pi$-delocalization within the ester fragment and between this fragment and the oxazole ring it imposes by forcing the ester group to be considerably skewed and out of the plane of the oxazole ring) accounts for the additional ca. $15 \mathrm{~kJ} \mathrm{~mol}^{-1}$ energy of conformer IV relative to III.

The relative energy of I and II is determined by the arrangement around the $\mathrm{C}_{17}-\mathrm{C}_{18}$ bond, mostly by the relative importance of the repulsive interactions between the two oxygen atoms of the ester group and the $\mathrm{N}$ and $\mathrm{O}$ atoms of the oxazole ring. All these four atoms are negatively charged, but it is clear from Figure 3, where the charges calculated from the atomic polar tensors (APT charges) for these four atoms and the distances between them in I and II are depicted, that the most important repulsive interaction occurs for conformer II, between the most negatively charged atom of each interacting fragment (the $\mathrm{O}_{3}$ atom of the oxazole ring and the $\mathrm{O}_{20}$ ester atom), which are also those separated by the shortest distance.

The calculated geometrical parameters for conformers I and II are provided in Table S1 (Supporting Information). Optimized 
geometries for all MCPOC conformers, in Cartesian coordinates, are given in Table $\mathrm{S} 2$.

Taking into account the calculated relative energies for the different MCPOC conformers, their populations can be estimated according to the Boltzmann statistics. At room temperature (298 $\mathrm{K})$ the I:II population ratio is $0.770: 0.230$, whereas the total population of conformers III and IV is smaller than $5 \times 10^{-4}$. At $323 \mathrm{~K}$, the temperature used to sublimate the compound in the matrix isolation spectroscopic experiments, the I:II population ratio slightly changes to $0.753: 0.246$, with the population of III being equal to 0.001 and that of IV less than $10^{-5}$. These results mean that only conformers I and II are experimentally accessible as isolated species. Moreover, at the temperature of the cold substrate of the cryostat $(10-20 \mathrm{~K})$, only the lowest energy conformer would subsist if the system could reach the thermodynamic equilibrium. However, the predicted barrier for the $\mathbf{I I} \rightarrow \mathbf{I}$ isomerization reaction is high enough $\left(20.5 \mathrm{~kJ} \mathrm{~mol}^{-1}\right.$; see Figure 2) to be significantly overcome during deposition at these temperatures and it can then be expected that the populations of the two most stable conformers existing in the vapor of the compound prior to deposition are efficiently trapped in the matrices; i.e., a I:II population ration of ca. 3:1 is expected to be observed in the as-deposited matrices.

Matrix Isolation FTIR Results. The mid-infrared spectra of MCPOC isolated in both argon and xenon matrices were obtained in the $4000-400 \mathrm{~cm}^{-1}$ range. The temperature of the vapor immediately prior to the deposition of the matrices was $323 \mathrm{~K}$, and the substrate temperature 10 and $20 \mathrm{~K}$, for argon and xenon matrices, respectively. The spectrum obtained in the argon matrix and the simulated spectrum obtained by summing the DFT(B3LYP)/6-311++G(d,p) predicted spectra of the experimentally relevant conformers I and II weighted by their expected populations $(0.75: 0.25)$ is provided in the Supporting Information as Figure S1. In the simulated spectrum, bands were represented by Lorentzian functions centered at the calculated wavenumbers scaled by 0.9835 and with fwhm (full width at half-maximum) equal to $2 \mathrm{~cm}^{-1}$. The simulated spectrum reproduces very well the experimental spectrum, providing strong evidence for the presence in the matrices of the two lowenergy MCPOC conformers in the expected population ratio. The as-deposited spectrum obtained in the xenon matrix is qualitatively identical to that obtained in argon. Results obtained in xenon were particularly useful for band assignment and conformer identification and will be discussed in detail later.

Both experimentally relevant conformers of MCPOC belong to the $C_{s}$ symmetry point group, with their 66 fundamental vibrations spanning the irreducible representations $44 \mathrm{~A}^{\prime}$ and $22 \mathrm{~A}^{\prime \prime}$, all being active in the infrared. Results of normal coordinates analysis based on the DFT(B3LYP)/6-311++G(d,p) calculated data are provided in Tables S3-S5 (Supporting Information). The definitions of the adopted internal coordinates are given in Table S3 and the calculated wavenumbers, infrared and Raman intensities, and potential energy distributions resulting from the normal-mode analysis carried out for I and II are presented in Tables S4 and S5, respectively.

As mentioned before, the predicted barrier for the $\mathbf{I I} \rightarrow \mathbf{I}$ isomerization $\left(20.5 \mathrm{~kJ} \mathrm{~mol}^{-1}\right)$ is high enough to prevent this reaction to take place during deposition of the matrices. Annealing of an argon matrix up to the maximum possible work temperature (ca. $40 \mathrm{~K}$; above this temperature the matrix starts to evaporate and looses its optical properties) did not allow for observation of any conformational isomerization as well. However, xenon matrices can be used in a considerably wider range of temperatures and, when $\mathrm{MCPOC}$ monomers isolated

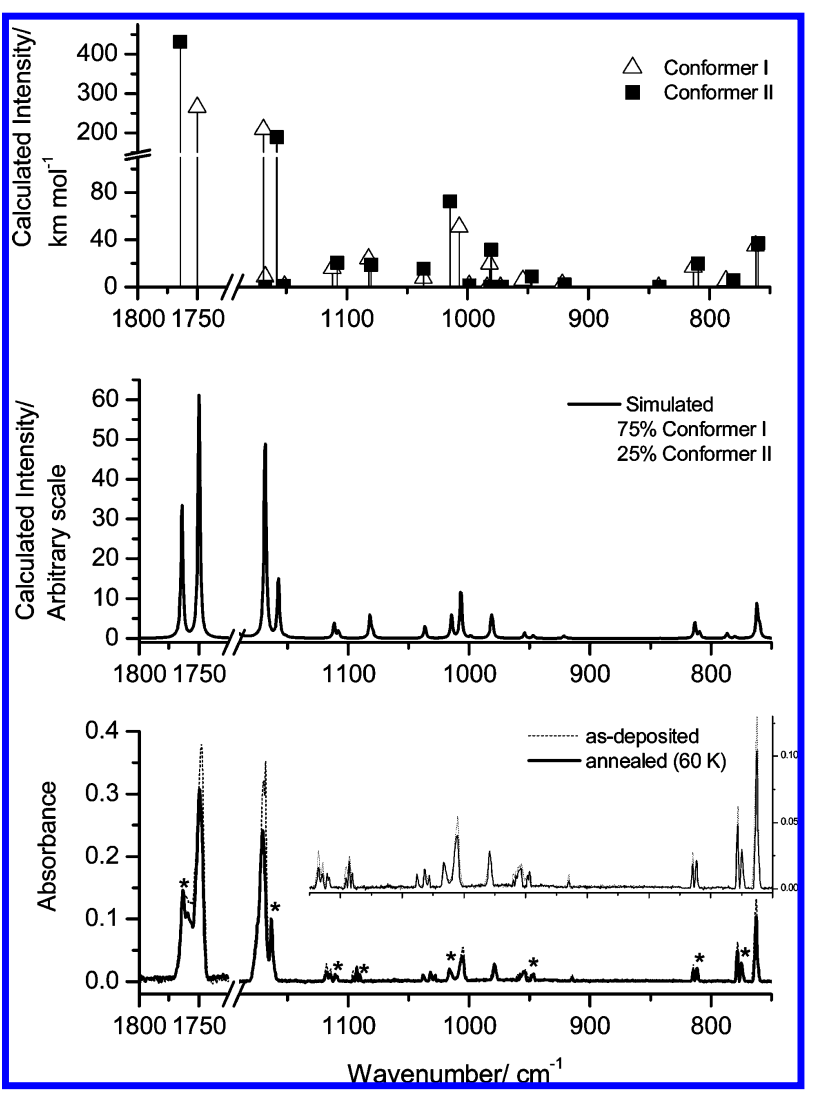

Figure 4. Top: Selected spectral regions (1800-1725 and 1180-700 $\mathrm{cm}^{-1}$ ) of the DFT(B3LYP)/6-311++G(d,p) calculated infrared spectra of MCPOC conformers I and II (stick spectra). Middle: Same spectral regions of the simulated spectrum obtained by summing the calculated spectra of I and II, weighted by their expected populations in the gas phase prior to deposition $(0.75: 0.25)$. In the simulated spectrum, bands were represented by Lorentzian functions centered at the calculated wavenumbers scaled by 0.9835 and with fwhm (full width at half-maximum) equal to $2 \mathrm{~cm}^{-1}$. Bottom: Same spectral regions of the infrared spectrum of MCPOC isolated in xenon matrix: (dashed line) spectrum of the as-deposited matrix (temperature of the vapor, $323 \mathrm{~K}$; substrate temperature, $20 \mathrm{~K}$ ); (solid line) spectrum of the annealed sample at $60 \mathrm{~K}$. The experimental spectra were normalized to the bands ascribed to conformer II (marked with asterisks), and bands due to aggregates were subtracted.

in this kind of matrix were annealed to ca. $60 \mathrm{~K}$, besides aggregation one could observe a redistribution of the intensities of the bands due to the monomers, indicating that their relative populations changed. According to the Barnes' relationship, ${ }^{66}$ this temperature is still significantly below that fitting the expectations for the temperature at which an isomerization reaction should start being observed for a process with an activation barrier of the order of that predicted for the $\mathbf{I I} \rightarrow \mathbf{I}$ gas phase isomerization. Indeed, the Barnes' relationship implies that such a temperature is about $70-75 \mathrm{~K}^{66}$ Such evidence indicates that the potential energy landscape for the matrixisolated compound is considerably different form that corresponding to the gas phase. Since the dipole moments of conformers I and II are significantly different (1.1 and 4.7 D, respectively), a different stabilization of the two conformers upon deposition in a matrix can be devised, in particular in the case of the highly polarizable xenon matrix, where conformer II can be expected to be considerably stabilized relative to form I. According to the experimental observations, the height of the energy barrier separating the two conformers seems also to be smaller than in the gas phase.

Figure 4 shows two selected spectral regions (1800-1725 and $1180-700 \mathrm{~cm}^{-1}$ ) of the infrared spectrum of the as- 
TABLE 1: Experimental (Matrix Isolation) and DFT(B3LYP)/6-311++G(d,p) Calculated Infrared Data for MCPOC and Vibrational Assignments Based on the Results of Normal Coordinate Analysis ${ }^{a}$

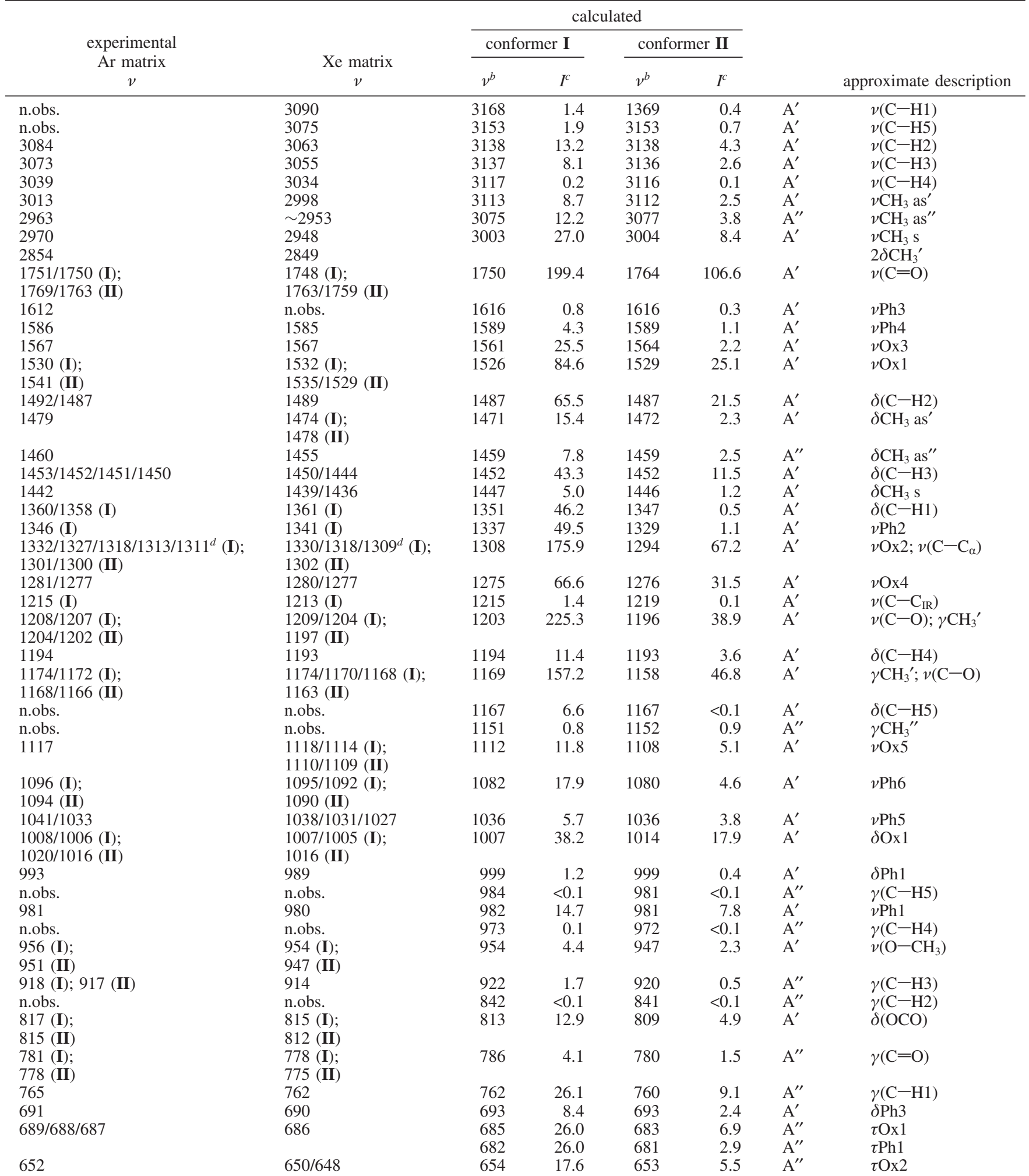

${ }^{a}$ Wavenumbers in $\mathrm{cm}^{-1}$. Calculated intensities in $\mathrm{km} \mathrm{mol}{ }^{-1}$. Key: $v$, bond stretching; $\delta$, bending; $\gamma$, rocking; w, wagging; $\tau$, torsion; $\mathrm{s}$, symmetric; as, asymmetric; IR, inter-ring; Ox, oxazole ring; Ph, phenyl ring; n.obs., not observed. See Table S3 (Supporting Information) for definition of internal coordinates and Tables S4 and S5 for potential energy distributions. ${ }^{b}$ Scaled wavenumbers $(0.9835)$. Intensities weighted by their expected populations: 0.75 (I) and 0.25 (II). ${ }^{d}$ Fermi resonance with $2 \tau \mathrm{Ox} 1$.

deposited xenon matrix of MCPOC (temperature of the vapor, $323 \mathrm{~K}$; substrate temperature $20 \mathrm{~K}$ ) and of the spectrum collected after annealing of the matrix at $60 \mathrm{~K}$. At this temperature, aggregation has already started and all bands due to the monomers decrease. However, two groups of bands could be easily identified in the spectra, with one group of bands reducing considerably more of intensity than the other one. The two experimental spectra shown in Figure 4 were normalized by the bands that reduce less of intensity, and bands due to aggregates were subtracted (the position of these bands was 
established doubtlessly by further annealing the matrix at a higher temperature, where aggregates are by far the dominant species). Figure 4 also shows the DFT(B3LYP)/6-311++G(d,p) calculated infrared spectra of MCPOC conformers I and II (stick spectra) and the simulated spectrum obtained by summing the calculated spectra of I and II, weighted by their expected populations in the gas phase prior to deposition (0.75: 0.25$)$. Two main conclusions result from the comparison of these spectra with the experimental ones: (1) the simulated spectrum fits very well the as-deposited spectrum of the compound in xenon matrix, demonstrating that no significant isomerization took place during deposition of the matrix and the gas phase equilibrium populations could be efficiently trapped in the matrix; (2) the bands that decreased more of intensity upon annealing fit nicely the spectrum of conformer $\mathbf{I}$, whereas those decreasing to a small extent can be doubtlessly ascribed to conformer II.

The different behavior of the bands due to each conformer upon annealing of the xenon matrix facilitated the assignment of the spectrum obtained in this matrix to the individual conformers. Comparison of the spectra obtained in the xenon matrix with that registered in argon then led to a prompt assignment of the latter. The proposed assignments are presented in Table 1.

The striking fact resulting from the temperature variation experiments carried out in the xenon matrix was the observation that it was conformer $\mathbf{I}$ that reduces its population faster upon annealing. There are two possible mechanisms that can explain the observations, which may opperate separately or simultaneously. The first implies that aggregation is facilitated in conformer I, relative to conformer II. Conformer selective aggregation was found for some matrix-isolated compounds, like dimethylglycine, ${ }^{67}$ dimethyl sulfite,${ }^{68}$ and 5-methyl- $1 \mathrm{H}, 3 \mathrm{H}$ pyrrolo[1,2-c][1,3]thiazole-6,7-dicarboxylate 2,2-dioxide. ${ }^{69}$ Though this mechanism alone can explain the observations, it is known that the more polar or smaller conformers are those that are more prone to exhibit a preferential aggregation. ${ }^{67-69} \mathrm{In}$ MCPOC, however, it is conformer II that is simultaneously more polar $(\mu=4.7 \mathrm{D}$ vs $1.1 \mathrm{D}$ in $\mathbf{I})$ and smaller (the calculated spatial extent of I and II is 4967 and 4821 au, respectively). The second mechanism, which we favor on the basis of the obtained experimental data and accumulated knowledge, ${ }^{67-71}$ would require that an inversion in the order of stability of the two conformers took place in the matrix media. Then, conformer I (most stable in the gas phase) would relax to form II upon annealing of the xenon matrix, where this latter form would be the most stable species. The necessary general conditions that need to be satisfied to make possible experimental observation of this inversion of the relative stability of conformers are (i) close energies of the conformers in the gas phase (with the less polar form being the most stable), (ii) significant differences in the dipole moments of the conformers, and (iii) accessible energy barriers for conformational isomerization. Both the first and second conditions above are fulfilled in the case of the relevant conformers of MCPOC, and it seems also possible that the energy barrier reduces in the matrix media to allow for conformational isomerization $(\mathbf{I} \rightarrow \mathbf{I I})$ to take place. Examples of inversion of the relative order of stability of conformers upon deposition of a compound in a matrix can be found in recent literature, e.g., for dimethylglycine methyl ester ${ }^{70}$ methyl cyanoacetate, ${ }^{71}$ and 5-methyl- $1 H, 3 H$-pyrrolo[ $[1,2-c][1,3]$ thiazole6,7-dicarboxylate 2,2-dioxide. ${ }^{69}$ The last compound is in fact a case where both selective aggregation and inversion of the order of stability of conformers were found to take place simultaneously.

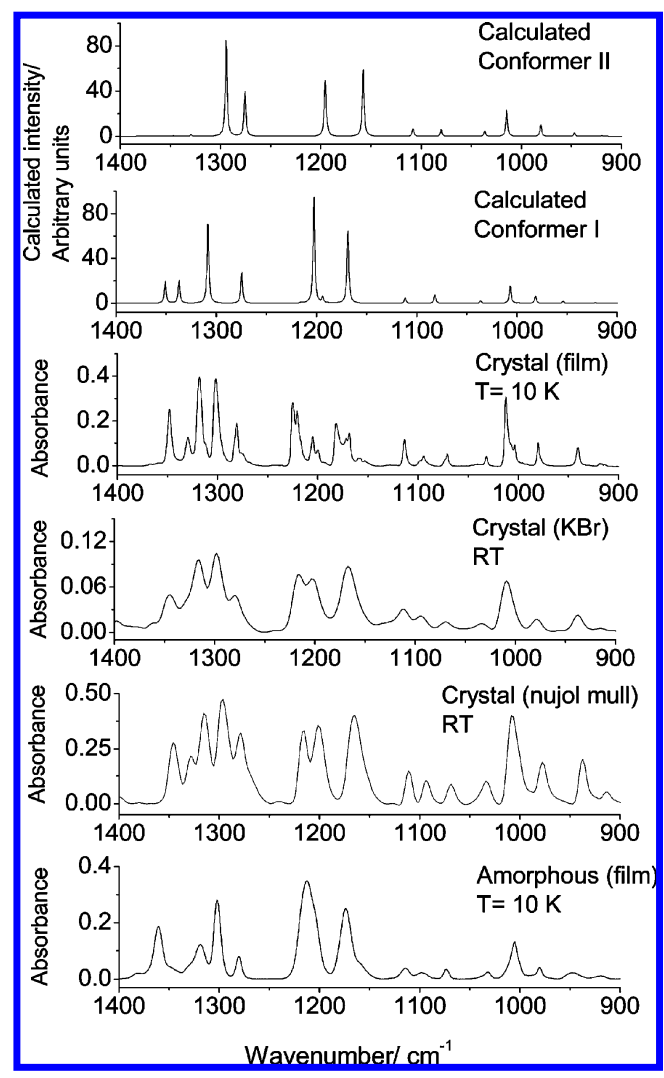

Figure 5. From bottom to top: $1400-900 \mathrm{~cm}^{-1}$ spectral range of the infrared spectra of MCPOC (i) in the amorphous layer resulting from fast deposition of the vapor of the compound at $343 \mathrm{~K}$ onto the cold substrate $(10 \mathrm{~K})$ of the cryostat; (ii) in the room temperature crystalline phase, as a Nujol mull; (iii) in the room temperature crystalline phase, as a $\mathrm{KBr}$ pellet; (iv) in the crystalline phase resulting from warming the amorphous layer to $280 \mathrm{~K}$, subsequently cooled to $10 \mathrm{~K}$; (v) and (vi) DFT(B3LYP)/6-311++G(d,p) calculated infrared spectra of conformers I and II, respectively. In the calculated spectra, bands were represented by Lorentzian functions centered at the calculated wavenumbers scaled by 0.9835 and with fwhm (full width at half-maximum) equal to $2 \mathrm{~cm}^{-1}$.

Spectroscopic Studies in the Neat Condensed Phases. The results discussed in the previous section indicated that the more polar conformer II of MCPOC is stabilized relative to form I upon deposition in matrices. To get additional information regarding the relative importance of the two conformers in more polar media, spectroscopic studies were also undertaken for the compound in neat condensed phases. Figure 5 presents a selected spectral range of the infrared spectra of MCPOC (i) in the amorphous layer resulting from fast deposition of the vapor of the compound at $343 \mathrm{~K}$ onto the cold substrate $(10 \mathrm{~K})$ of the cryostat, (ii) in the room temperature crystalline phase, both as a $\mathrm{KBr}$ pellet and as a Nujol mull, and (iii) in the crystalline phase resulting from warming the amorphous layer to $280 \mathrm{~K}$, subsequently cooled to $10 \mathrm{~K}$. These spectra are compared with the DFT(B3LYP)/6-311++G(d,p) calculated infrared spectra of conformers I and II. Full range spectra are presented in Figure S2 (Supporting Information), where the spectrum of the crystalline phase recorded immediately after its formation from the amorphous state at $280 \mathrm{~K}$ is also presented.

As could be anticipated, the spectrum of the amorphous phase has characteristically broad bands due to both the presence of the two conformers and significant disorder. The bands at 1361, 1330 , and $1318 \mathrm{~cm}^{-1}$ can be assigned mainly to conformer I (compare the experimental spectrum with those calculated for the two conformers; Figure 5), whereas that observed at 1302 
TABLE 2: Assignment of the Vibrational Spectra of MCPOC in the Neat Condensed Phases ${ }^{a}$

\begin{tabular}{|c|c|c|c|c|}
\hline $\begin{array}{l}\text { Approximate } \\
\text { Description }\end{array}$ & $\begin{array}{l}\text { IR Glass } \\
(10 \mathrm{~K})\end{array}$ & $\begin{array}{l}\text { IR Crystal } \\
\text { (RT; KBr) }\end{array}$ & $\begin{array}{l}\text { IR Crystal } \\
(10 \mathrm{~K})\end{array}$ & $\begin{array}{l}\text { Raman Crystal } \\
\text { (RT) }\end{array}$ \\
\hline$v(\mathrm{C}-\mathrm{H} 1)$ & & & 3098 & \\
\hline$v(\mathrm{C}-\mathrm{H} 5)$ & & & 3093 & 3077 \\
\hline$v(\mathrm{C}-\mathrm{H} 2)$ & 3067 & 3066 & 3079 & \\
\hline$v(\mathrm{C}-\mathrm{H} 3)$ & & & 3069 & \\
\hline$v(\mathrm{C}-\mathrm{H} 4)$ & & & 3057 & 3056 \\
\hline$v \mathrm{CH}_{3}$ as' & 3037 & 3034 & 3034 & 3035 \\
\hline $\mathrm{vCH}_{3}$ as" & 3005 & 3014 & 3013 & 3013 \\
\hline $\mathrm{vCH}_{3} \mathrm{~s}$ & 2956 & 2956 & 2957 & 2958 \\
\hline $2 \delta \mathrm{CH}_{3}$ & 2849 & 2849 & 2849 & 2849 \\
\hline$v(\mathrm{C}=\mathrm{O})$ & 1743 & 1738 & $\begin{array}{l}1736(\mathbf{I}) \\
1740(\mathbf{I I})\end{array}$ & 1740 \\
\hline$v \mathrm{Ph} 3$ & 1608 & 1607 & 1607 & 1606 \\
\hline $\mathrm{vPh} 4$ & 1585 & 1577 & 1585 & 1585 \\
\hline vOx3 & 1566 & 1558 & $\begin{array}{l}1553(\mathbf{I}) \\
1567(\mathbf{I I})\end{array}$ & 1566 \\
\hline vOx1 & 1530 & $\begin{array}{l}1530(\mathbf{I}) \\
1542(\mathbf{I I})\end{array}$ & $\begin{array}{l}1532(\mathbf{I}) \\
1541(\mathbf{I I})\end{array}$ & 1531 \\
\hline$\delta(\mathrm{C}-\mathrm{H} 2)$ & 1490 & 1510 & 1485 & 1499 \\
\hline$\delta \mathrm{CH}_{3}$ as & 1484 & 1484 & n.obs. & 1484 \\
\hline$\delta \mathrm{CH}_{3}$ as" & 1459 & 1458 & $1459 / 1455$ & 1458 \\
\hline$\delta(\mathrm{C}-\mathrm{H} 3)$ & 1450 & 1449 & $1448 / 1447$ & 1449 \\
\hline$\delta \mathrm{CH}_{3} \mathrm{~s}$ & 1438 & 1437 & 1438 & 1439 \\
\hline$\delta(\mathrm{C}-\mathrm{H} 1)$ & $1361(\mathbf{I})$ & $1362(\mathbf{I})$ & $1361(\mathbf{I})$ & 1369 \\
\hline$v \mathrm{Ph} 2$ & $1348($ I $)$ & $1345(\mathbf{I})$ & $1348(\mathbf{I})$ & 1347 \\
\hline$v O \times 2 ; v\left(C-C_{0}\right)$ & $\begin{array}{l}1330 / 1319(\mathbf{I}) \\
1302(\mathbf{I I})\end{array}$ & $\begin{array}{l}\text { 1330/1316(I); } \\
1298(\text { II })\end{array}$ & $\begin{array}{l}\text { 1330/1318/1312(I); } \\
1302 \text { (II) }\end{array}$ & $\begin{array}{l}1316(\mathbf{I}) \\
1299(\mathbf{I I})\end{array}$ \\
\hline $\mathrm{vOx} 4$ & 1281 & 1280 & $1283 / 1280$ & 1280 \\
\hline$v\left(\mathrm{C}-\mathrm{C}_{\mathrm{TR}}\right)$ & 1212 & 1216 & $\begin{array}{l}1225 \text { (I); } \\
1221 \text { (II) }\end{array}$ & 1215 \\
\hline$v(\mathrm{C}-\mathrm{O}) ; \gamma \mathrm{CH}_{3}$ & 1204 & 1203 & $\begin{array}{l}1205(\mathbf{I}) \\
1201(\mathbf{I I})\end{array}$ & 1202 \\
\hline$\delta(\mathrm{C}-\mathrm{H} 4)$ & n.obs. & n.obs. & n.obs. & n.obs. \\
\hline$\gamma \mathrm{CH}_{3}^{\prime} ; v(\mathrm{C}-\mathrm{O})$ & 1174 & 1174 & $\begin{array}{l}1182(\mathbf{I}) \\
1172 / 1168(\mathbf{I I})\end{array}$ & $\begin{array}{l}1182 \\
1168\end{array}$ \\
\hline$\delta(\mathrm{C}-\mathrm{H} 5)$ & 1158 & 1158 & 1158 & 1160 \\
\hline $\mathrm{\gamma CH}_{3}{ }^{\prime \prime}$ & n.obs. & n.obs. & 1152 & n.obs. \\
\hline $10 \times 5$ & 1114 & 1111 & 1114 & 1112 \\
\hline vPh6 & 1098 & 1094 & $\begin{array}{l}1099(\mathbf{I}) \\
1095(\mathbf{I I})\end{array}$ & 1095 \\
\hline $2 v(\mathrm{C}-\mathrm{Cl})$ & 1074 & 1070 & $1073 / 1070$ & 1071 \\
\hline$v \mathrm{Ph} 5$ & 1032 & 1034 & 1032 & 1034 \\
\hline$\delta \mathrm{Ox} 1$ & 1005 & 1008 & $\begin{array}{l}1007 / 1003(\mathbf{I}) \\
1012(\mathbf{I I})\end{array}$ & 1004 \\
\hline$\delta \mathrm{Ph} 1$ & n.obs. & n.obs. & n.obs. & \\
\hline$\gamma(\mathrm{C}-\mathrm{H} 5)$ & n.obs. & n.obs. & n.obs. & n.obs. \\
\hline $\mathrm{vPh} 1$ & 980 & 979 & 980 & 979 \\
\hline$\gamma(\mathrm{C}-\mathrm{H} 4)$ & n.obs. & n.obs. & n.obs. & n.obs. \\
\hline$v\left(\mathrm{O}-\mathrm{CH}_{3}\right)$ & 948 & 937 & 940 & 938 \\
\hline$\gamma(\mathrm{C}-\mathrm{H} 3)$ & 919 & 915 & $918 / 913$ & n.obs. \\
\hline$\gamma(\mathrm{C}-\mathrm{H} 2)$ & 844 & 834 & 840 & 841 \\
\hline$\delta(\mathrm{OCO})$ & 817 & 813 & 815 & 813 \\
\hline$\gamma(\mathrm{C}=\mathrm{O})$ & 778 & 774 & $778 / 776$ & n.obs. \\
\hline$\gamma(\mathrm{C}-\mathrm{H} 1)$ & 766 & 766 & 770 & 769 \\
\hline ¿Ph3 & & & 692 & \\
\hline$\tau \mathrm{Ox} 1$ & 691 & 687 & 686 & 687 \\
\hline$\tau \mathrm{Ph} 1$ & & & 682 & \\
\hline$\tau \mathrm{O} \times 2$ & 650 & 646 & 645 & 646 \\
\hline$\delta \mathrm{Ph} 2$ & 619 & 622 & 617 & 619 \\
\hline $\mathrm{w}(\mathrm{Ox}-\mathrm{Ph})$ & 590 & 603 & 595 & 595 \\
\hline
\end{tabular}

${ }^{a}$ Wavenumbers in $\mathrm{cm}^{-1}$. Key: $\nu$, bond stretching; $\delta$, bending; $\gamma$ rocking; $\tau$ torsion; w, wagging; s, symmetric; as, asymmetric; n.obs., not observed; n.i., not investigated. See Table S3 (Supporting Information) for definition of coordinates. ${ }^{b}$ Combined with w(Ph-Ox) in I and with $\delta\left(\mathrm{C}-\mathrm{O}-\mathrm{CH}_{3}\right)$ in II (see Tables $\mathrm{S} 4$ and $\mathrm{S} 5$, Supporting Information).

$\mathrm{cm}^{-1}$ is a band mark of conformer II. All the other bands shall contain contributions from both conformers. Upon crystallization of the amorphous phase (at ca. $280 \mathrm{~K}$ ), the spectrum changes considerably (see Figure S2, Supporting Information). Recooling the sample to $10 \mathrm{~K}$ did not lead to further changes, except some further band narrowing. The $10 \mathrm{~K}$ spectrum of the crystalline 
phase obtained from the amorphous film (Figure 5) clearly reveals bands due to both conformers (see Table 2 for assignments). For example, besides the bands at 1348, 1330, and 1318 $\mathrm{cm}^{-1}$, which relates to those observed and 1361, 1330, and 1318 $\mathrm{cm}^{-1}$ in the spectrum of the amorphous phase, other bands ascribable to conformer I are also observed at 1225, 1205, 1182, 1073 , and $1007 / 1003 \mathrm{~cm}^{-1}$, while bands due to conformer II are observed at 1302, 1221, 1201, 1172/1168, 1070, and 1012 $\mathrm{cm}^{-1}$. From the intensity of the bands at $1318 \mathrm{~cm}^{-1}$ (I) and $1302 \mathrm{~cm}^{-1}$ (II), which are well separated and intense bands in the spectrum of the crystalline phase, a rough estimation of the relative population of molecules with conformation I and II in that phase could be obtained. The results indicate that the two conformations are essentially equally populated (I:II population ratio: $0.92 \pm 0.1$ ) i.e., they are compatible with a crystalline phase where both conformers exist in a 1:1 ratio. The spectra of the crystal at room temperature (both in $\mathrm{KBr}$ pellet and in Nujol) are qualitatively identical to that of the crystal at low temperature, though, as expected, exhibiting bands considerably broader.

Comparison of the Raman spectrum of the crystal at room temperature with those calculated for I and II (Figure S3; Supporting Information), is also in agreement with the presence of the two conformers in the crystalline phase of MCPOC (see also Table 2), though the greater similarity of the Raman spectra of the individual conformers (the most conformationally characteristic Raman bands have very low intensities) makes these spectra less informative than the infrared spectra regarding this question.

On the whole, the results obtained for the neat condensed phases of MCPOC agree with the information obtained from the matrixisolation studies regarding the stabilization of conformer II in more polar environments compared to gas phase.

\section{Conclusion}

The conformational preferences and spectroscopic properties of methyl 4-chloro-5-phenyl-1,3-oxazole-2-carboxylate (MCPOC) have been studied by FTIR spectroscopy for the compound isolated in cryogenic matrices (argon; xenon) and in neat condensed phases. The experimental studies were complemented with DFT(B3LYP)/6-311++G(d,p) calculations. Two experimentally relevant low-energy conformers (I and II) of the molecule were identified. These conformers differ from each other in the orientation of the ester group relative to the oxazole ring. In both conformers, the ester moiety was found to be in the s-cis configuration $\left(\mathrm{O}=\mathrm{C}-\mathrm{O}-\mathrm{CH}_{3}\right.$ dihedral: $\left.0^{\circ}\right)$. In the gas phase, conformer $\mathbf{I}$ is ca. $3.0 \mathrm{~kJ} \mathrm{~mol}^{-1}$ more stable than form II, corresponding to a room temperature I:II relative population of ca. 3. Two additional higher energy conformers, III and IV, of no experimental relevance, with relative energies of ca. 30 and $45 \mathrm{~kJ} \mathrm{~mol}^{-1}$, respectively, were also predicted to exist by the calculations, corresponding to structures where the ester group is in an approximately s-trans arrangement.

Annealing of the compound isolated in xenon at $60 \mathrm{~K}$ led to aggregation and simultaneous reduction of the population of $\mathbf{I}$ compared to that of the more polar conformer II. These results suggest the inversion of the order of stability of the two conformers in that matrix, eventually accompanied by a higher trend of conformer I to aggregate. In agreement with these results, in the crystalline phase of the compound, the presence of both conformers in a 1:1 population ratio was testified by both infrared and Raman spectroscopy. Full assignment of the observed infrared bands to the two experimentally accessible conformers was carried out for the matrix isolated monomeric species. In addition, the infrared spectra of the neat compound in the low-temperature $(10 \mathrm{~K})$ amorphous and crystalline phases, as well as the infrared and Raman spectra of the crystal at room temperature, were also assigned.

Acknowledgment. This work has been funded by the Portuguese Science Foundation (FCT, Lisbon), under research project PTDC/QUI/71203/2006. S.L. and C.M.N. also thank FCT for the Ph.D. Grants \#SFRH/BD/29698/2006 and \#SFRH/ BD/28844/2006. A.G.-Z. thanks also to ANCPCyT (Project PICT(2006)/00068) and CYTED (Network 108RT0362) for partial financial support. A.G.Z. is member of the Research Career Conicet, Argentina.

Supporting Information Available: Figure S1, infrared spectrum of MCPOC isolated in an argon matrix and simulated spectra calculated based on the theoretically obtained spectra of conformers I and II. Figure S2, room temperature infrared spectra of neat crystalline MCPOC ( $\mathrm{KBr}$ pellet), low-temperature amorphous and crystalline phase, and B3LYP/6-311++G(d,p) calculated infrared spectra for conformers I and II. Figure S3, room temperature Raman spectrum of neat crystalline MCPOC and B3LYP/6-311++G(d,p) calculated Raman spectra for conformers I and II. Table 1, geometry of the two MCPOC most stable conformers calculated at the B3LYP/6-311++G(d,p) level of theory. Table S2, Cartesian coordinates for optimized minimum energy structures of MCPOC. Table S3, definition of internal coordinates used in the normal-mode analysis of MCPOC. Tables S4 and S5, B3LYP/6-311++G(d,p) calculated spectroscopic data and results of normal coordinate analysis for the two most stable, experimentally relevant conformers of MCPOC (forms I and II). This material is available free of charge via the Internet at http:// pubs.acs.org.

\section{References and Notes}

(1) Fusetani, N.; Matsunaga, S. Chem. Rev. 1993, 93, 1793.

(2) Adamczeski, M.; Quinoà, E.; Crews, P. J. Am. Chem. Soc. 1988, $110,1598$.

(3) Purvis, M. B.; Kingston, D. G. I.; Fujii, N.; Floss, H. G. J. Chem. Soc., Chem. Commun. 1987, 302.

(4) Kato, Y.; Fusetani, N.; Matsunaga, S.; Hashimoto, K.; Fujita, S.; Furuya, T. J. Am. Chem. Soc. 1986, 108, 2780.

(5) Sanz, C.; Ansorena, D.; Bello, J.; Cid, C. J. Agric. Food Chem. 2001, 49, 1364.

(6) Lee, M.-H.; Ho, Ch.-Tang; Chang, S. S. J. Agric. Food Chem. 1981, $29,686$.

(7) Jin, Z. Nat. Prod. Rep. 2003, 20, 584

(8) Lewis, J. R. Nat. Prod. Rep. 2002, 19, 223.

(9) Maga, J. A. J. Agric. Food Chem. 1978, 26, 1049.

(10) Yeh, V. S. C. Tetrahedron 2004, 60, 11995.

(11) Hamada, Y.; Shioiri, T. Chem. Rev. 2005, 105, 4441.

(12) Wipf, P. Chem. Rev. 1995, 95, 2115.

(13) Williams, A. B.; Jacobs, R. S. Cancer Lett. 1993, 71, 97

(14) Bertram, A.; Pattenden, G. Nat. Prod. Rep. 2007, 24, 18.

(15) Bertram, A.; Maulucci, N.; New, O. M.; Nor, S. M. M.; Pattenden, G. Org. Biomol. Chem. 2007, 5, 1541.

(16) Ichino, T.; Arimoto, H.; Uemura, D. Chem. Commun. 2006, 1742.

(17) Bull, J. A.; Balskus, E. P.; Horan, R. A. J.; Langner, M.; Ley, S. V. Angew. Chem., Int. Ed. 2006, 45, 6714.

(18) Yokokawa, F.; Asano, T.; Shioiri, T. Org. Lett. 2000, 2, 4169.

(19) Unangst, P. C.; Connor, D. T.; Cetenko, W. A.; Sorenson, R. J.; Kostlan, C. R.; Sircar, J. C.; Wright, C. D.; Schrier, D. J.; Dyer, R. D. J. Med. Chem. 1994, 37, 322.

(20) Zhou, X.-Ping; Zhang, M.-Xin; Sun, W.; Yang, X.-Hong; Wang, G.-Shu; Sui, Da-Yuan; Yu, X.-Feng; Qu, S.-Chun Biol. Pharm. Bull. 2009, $32,1986$.

(21) Brown, P.; Davis, D. T.; O’Hanlon, P.; Wilson, J. M. J. Med. Chem. 1996, 39, 446.

(22) Milne, J. C.; Eliot, A. C.; Kelleher, N. L.; Walsh, C. T. Biochemistry 1998, 37, 13250

(23) Stankova, I. G.; Videnov, G. I.; Golovinsky, E. V.; Jung, G. J. Peptide Sci. 1999, 5, 392.

(24) Kozikowski, A. P.; Hasan, N. J. Org. Chem. 1977, 42, 2039. 
(25) You, S.-Li; Kelly, J. W. J. Org. Chem. 2003, 68, 9506.

(26) Gursöy, A.; Demirayak, Ş.; Çapan, G.; Erol, K.; Vural, K. Eur. J. Med. Chem. 2000, 35, 359.

(27) Vincze, Á.; Solymosi, J.; Kása, I.; Safrany, Á. Radiat. Phvs. Chem. 2007, 76, 1395.

(28) Sodaye, S.; Scindia, Y. M.; Pandey, A. K.; Reddy, A. V. R. Sens. Actuators B 2007, 123, 50.

(29) Tang, J. S.; Verkade, J. G. J. Org. Chem. 1996, 61, 8750.

(30) Kikkeri, R.; Traboulsi, H.; Humbert, N.; Gumienna-Kontecka, E.; Arad-Yellin, R.; Melman, G.; Elhabiri, M.; Albrecht-Gary, A.-M.; Shanzer,

A. Inorg. Chem. 2007, 46, 2485.

(31) El-Aal, R. M. A. Dyes Pigm. 2004, 61, 251.

(32) Turchi, I. J.; Dewar, M. J. S. Chem. Rev. 1975, 75, 389.

(33) Schiketanz, I.; Racoveanuschiketanz, A.; Gheorghiu, M. D.; Bala-

ban, A. T. Rev. Roum. Chim. 1992, 37, 1315.

(34) Belenkii, L. I.; Bogdanov, V. S.; Abronin, I. A.; Gromova, G. P.; Cheskis, M. A.; Zakharyan, R. Z. Chem. Scripta 1985, 25, 266.

(35) Jwazwinski, J.; Kamienski, B.; Staszewska-Krajewska, O.; Webb,

G. A. J. Mol. Struct. 2003, 646, 1.

(36) Palmer, M. H. J. Mol. Struct. 2007, 834-836, 113.

(37) Muniz-Miranda, M. Vibr. Spectrosc. 1999, 18, 227.

(38) Elazhary, A. A.; Ghoneim, A. A.; Elshakre, M. E. J. Chem. Res. 1995, 9, 354 .

(39) Shaffer, A. A.; Wiershchke, S. G. J. Comput. Chem. 1993, 14, 75

(40) Heinemann, F. W.; Dolling, W.; Gildenast, T.; Hartung, H. J. Chem. Crystallogr. 1995, 25, 237.

(41) Kaiser, D.; Videnov, G.; Maihle-Mossmer, C.; Strahle, J.; Jung, G. J. Chem Soc., Perkin Trans. 2 2000, 5, 1081.

(42) Lee, J. C.; Seo, J. W.; Baek, J. K. Synth. Commun. 2007, 37, 2159.

(43) Dabholkar, V. V.; Mishra, S. K. J. Heterocycl. Commun. 2006, 12,241 .

(44) Li, B.; Buzon, R. A.; Zhang, Z. Org. Process Res. Dev. 2007, 11, 951.

(45) Lachia, M.; Moody, C. J. Nat. Prod. Rep. 2008, 25, 227.

(46) Lopes, S.; Nunes, C. M.; Fausto, R.; Pinho e Melo, T. M. V. D. J. Mol. Struct. 2009, 919, 47.

(47) Pinho e Melo, T. M. V. D.; Lopes, C. S.; Rocha Gonsalves, A. M. d'A.; Storr, R. C. Synthesis. 2002, 605.

(48) Frisch, M. J.; Trucks, G. W.; Schlegel, H. B.; Scuseria, G. E.; Robb, M. A.; Cheeseman, J. R.; Montgomery, J. A., Jr.; Vreven, T.; Kudin, K. N.; Burant, J. C.; Millam, J. M.; Iyengar, S. S.; Tomasi, J.; Barone, V.; Mennucci, B.; Cossi, M.; Scalmani, G.; Rega, N.; Petersson, G. A.; Nakatsuji, H.; Hada, M.; Ehara, M.; Toyota, K.; Fukuda, R.; Hasegawa, J.; Ishida, M.; Nakajima, T.; Honda, Y.; Kitao, O.; Nakai, H.; Klene, M.; Li, X.; Knox, J. E.; Hratchian, H. P.; Cross, J. B.; Bakken, V.; Adamo, C.; Jaramillo, J.; Gomperts, R.; Stratmann, R. E.; Yazyev, O.; Austin, A. J.;
Cammi, R.; Pomelli, C.; Ochterski, J. W.; Ayala, P. Y.; Morokuma, K.; Voth, G. A.; Salvador, P.; Dannenberg, J. J.; Zakrzewski, V. G.; Dapprich, S.; Daniels, A. D.; Strain, M. C.; Farkas, O.; Malick, D. K.; Rabuck, A. D.; Raghavachari, K.; Foresman, J. B.; Ortiz, J. V.; Cui, Q.; Baboul, A. G.; Clifford, S.; Cioslowski, J.; Stefanov, B. B.; Liu, G.; Liashenko, A.; Piskorz, P.; Komaromi, I.; Martin, R. L.; Fox, D. J.; Keith, T.; Al-Laham, M. A.; Peng, C. Y.; Nanayakkara, A.; Challacombe, M.; Gill, P. M. W.; Johnson, B.; Chen, W.; Wong, M. W.; Gonzalez, C.; Pople, J. A. Gaussian 03, Revision C.02; Gaussian, Inc.: Wallingford, CT, 2004.

(49) Frisch, M.; Head-Gordon, M.; Pople, J. Chem. Phvs. Lett. 1990, $166,281$.

(50) Becke, A. D. Phvs. Rev. A. 1988, 38, 3098.

(51) Lee, C. T.; Yang, W. T.; Parr, R. G. Phys. Rev. B 1988, 37, 785.

(52) Csaszar, P.; Pulay, P. J. Mol. Struct. (THEOCHEM) 1984, 114, 31 .

(53) Farkas, Ö.; Schlegel, H. B. J. Chem Phys. 1999, 111, 10806.

(54) Peng, C.; Schlegel, H. B. Isr. J. Chem. 1994, 33, 449.

(55) Michalska, D.; Wysokinski, R. Chem. Phys. Lett. 2005, 403, 211.

(56) Schachtschneider, J. H. Technical Report. Shell Development Co.: Emeryville, CA, 1969.

(57) Pulay, P.; Fogarasi, G.; Pang, F.; Boggs, J. E. J. Am. Chem. Soc 1979, 110,2550

(58) Gómez-Zavaglia, A.; Kaczor, A.; Cardoso, A. L.; Pinho e Melo,

T. M. V. D.; Fausto, R. J. Phys. Chem. A 2006, 110, 10742.

(59) Gómez-Zavaglia, A.; Kaczor, A.; Cardoso, A. L.; Pinho e Melo,

T. M. V. D.; Fausto, R. J.Phys. Chem. A 2006, $110,8081$.

(60) Jarmelo, S.; Fausto, R. J. Mol. Struct. 1999, 509, 183.

(61) Fausto, R.; Teixeira-Dias, J. J. C. J. Mol. Struct. 1987, 150, 381

(62) Fausto, R.; Teixeira-Dias, J. J. C. J. Mol. Struct. 1986, 144, 215.

(63) Fausto, R.; Teixeira-Dias, J. J. C. J. Mol. Struct. 1986, 144, 225.

(64) Teixeira-Dias, J. J. C.; Fausto, R. J. Mol. Struct. (THEOCHEM)

1993, $282,123$.

(65) Neta, J. M. F.; Fausto, R. J. Mol. Struct. 1998, 443, 41.

(66) Barnes, A. J. J. Mol. Struct. 1984, 113, 161.

(67) Gómez-Zavaglia, A.; Reva, I. D.; Fausto, R. Phys. Chem. Chem. Phvs. 2003, 5, 41.

(68) Borba, A.; Gómez-Zavaglia, A.; Fausto, R. J. Mol. Struct. 2006, 794, 196.

(69) Kaczor, A.; Pinho e Melo, T. M. V. D.; Soares, M. I.; Fausto, R. J. Phvs. Chem. A, 2006, 110, 6531 .

(70) Gómez-Zavaglia, A.; Fausto, R. Phys. Chem. Chem. Phys. 2003, 5,52 .

(71) Reva, I. D.; Stepanian, S. G.; Adamowicz, L.; Fausto, R. Chem. Phys. Lett. 2003, 374, 631.

JP103665B 